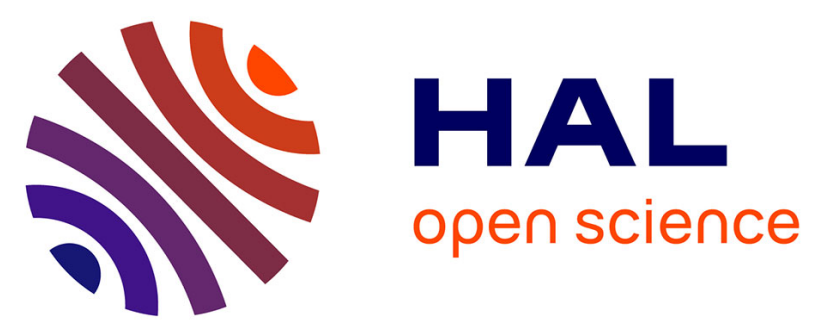

\title{
Long-term intake of 9-PAHPA or 9-OAHPA modulates favorably the basal metabolism and exerts an insulin sensitizing effect in obesogenic diet-fed mice
}

Melha Benlebna, Laurence Balas, Béatrice Bonafos, Laurence Pessemesse, Gilles Fouret, Claire Vigor, Sylvie Gaillet, Jacques Grober, Florence Bernex, Jean-Francois Landrier, et al.

\section{To cite this version:}

Melha Benlebna, Laurence Balas, Béatrice Bonafos, Laurence Pessemesse, Gilles Fouret, et al.. Longterm intake of 9-PAHPA or 9-OAHPA modulates favorably the basal metabolism and exerts an insulin sensitizing effect in obesogenic diet-fed mice. European Journal of Nutrition, 2021, 60 (2013-2027), 10.1007/s00394-020-02391-1 . hal-02962441

\section{HAL Id: hal-02962441 \\ https://hal.inrae.fr/hal-02962441}

Submitted on 16 Dec 2020

HAL is a multi-disciplinary open access archive for the deposit and dissemination of scientific research documents, whether they are published or not. The documents may come from teaching and research institutions in France or abroad, or from public or private research centers.
L'archive ouverte pluridisciplinaire HAL, est destinée au dépôt et à la diffusion de documents scientifiques de niveau recherche, publiés ou non, émanant des établissements d'enseignement et de recherche français ou étrangers, des laboratoires publics ou privés. 


\title{
Long-term intake of 9-PAHPA or 9-OAHPA modulates favorably the basal metabolism and exerts an insulin sensitizing effect in obesogenic diet-fed mice
}

\author{
Melha Benlebna ${ }^{1}$. Laurence Balas ${ }^{2}$. Béatrice Bonafos ${ }^{1}$. Laurence Pessemesse ${ }^{1}$. Gilles Fouret ${ }^{1}$. Claire Vigor ${ }^{2}$. \\ Sylvie Gaillet ${ }^{1}$. Jacques Grober ${ }^{3} \cdot$ Florence Bernex $^{4}$. Jean-François Landrier ${ }^{5}$. Ondrej Kuda ${ }^{6} \cdot$ Thierry Durand $^{2}$. \\ Charles Coudray ${ }^{1} \cdot$ François Casas $^{1} \cdot$ Christine Feillet-Coudray $^{1}$ (i)
}

Received: 16 June 2020 / Accepted: 14 September 2020

\begin{abstract}
Purpose Fatty acid esters of hydroxy fatty acids (FAHFAs) are a large family of endogenous bioactive lipids. To date, most of the studied FAHFAs are branched regioisomers of Palmitic Acid Hydroxyl Stearic Acid (PAHSA) that were reported to possess anti-diabetic and anti-inflammatory activity in humans and rodents. Recently, we have demonstrated that 9-PAHPA or 9-OAHPA intake increased basal metabolism and enhanced insulin sensitivity in healthy control diet-fed mice but induced liver damage in some mice. The present work aims to explore whether a long-term intake of 9-PAHPA or 9-OAHPA may have similar effects in obesogenic diet-fed mice.

Methods C57B16 mice were fed with a control or high fat-high sugar (HFHS) diets for 12 weeks. The HFHS diet was supplemented or not with 9-PAHPA or 9-OAHPA. Whole-body metabolism was explored. Glucose and lipid metabolism as well as mitochondrial activity and oxidative stress status were analyzed.

Results As expected, the intake of HFHS diet led to obesity and lower insulin sensitivity with minor effects on liver parameters. The long-term intake of 9-PAHPA or 9-OAHPA modulated favorably the basal metabolism and improved insulin sensitivity as measured by insulin tolerance test. On the contrary to what we have reported previously in healthy mice, no marked effect for these FAHFAs was observed on liver metabolism of obese diabetic mice.

Conclusion This study indicates that both 9-PAHPA and 9-OAHPA may have interesting insulin-sensitizing effects in obese mice with lower insulin sensitivity.
\end{abstract}

Keywords FAHFA $\cdot$ Basal metabolism $\cdot$ Insulin sensitivity $\cdot$ Liver steatosis $\cdot$ Mitochondria $\cdot$ Oxidative stress mice

Electronic supplementary material The online version of this article ( ) contains supplementary material, which is available to authorized users.

\section{Christine Feillet-Coudray}

christine.coudray@inrae.fr

DMEM, INRAE, Univ Montpellier, Montpellier, France

2 Institut Des Biomolécules Max Mousseron (IBMM), Université de Montpellier, CNRS, ENSCM, Montpellier, France

3 LNC UMR1231, INSERM, Univ Bourgogne Franche-Comté, Agrosup Dijon, LipSTIC LabEx, Dijon, France

\section{Introduction}

The burden of nutrition-related chronic diseases is rapidly increasing worldwide [1]. It is well known that the excessive energy consumption and the reduction of physical activity are determining factors in the prevalence of these diseases.

4 INSERM, U1194, Network of Experimental Histology, BioCampus, CNRS, UMS3426, Montpellier, France

5 Aix Marseille Univ, INSERM, INRAE, C2VN, Marseille, France

6 Department of Metabolism of Bioactive Lipids, Institute of Physiology of the Czech Academy of Sciences, Videnska 1083, 14220 Prague, Czech Republic 
An energy-rich diet such as a diet high in fats and sugars, combined with sedentarily, may induce an energy imbalance responsible for weight gain and obesity. Overweight and obesity are the main causes of the development of metabolic disorders such as type 2 diabetes, hepatic steatosis and cardiovascular diseases, which can lead to significant morbidity and mortality [2]. Recently, the International Diabetes Federation estimated that 463 million people in 2019 were affected diabetes worldwide, representing approximately 4.2 million deaths and an estimated $\$ 760$ billion in health care costs [3, 4]. Non-alcoholic fatty liver disease (NAFLD) is an other emerging global health issue which represents a potential risk factor for insulin resistance and type 2 diabetes [5]. Indeed, over $75 \%$ of patients with type 2 diabetes are afflicted of NAFLD [6].

Recently, Branched Fatty Acid esters of Hydroxy Fatty Acids (FAHFAs), a class of endogenous bioactive lipids in mammals, has emerged as a new opportunity of treatment for diabetes and inflammatory diseases. FAHFAs are present in many foods [7, 8]. As there are naturally many fatty acids (FAs) and many hydroxylated fatty acids (HFAs), multiple possible combinations exist and about 50 families of FAHFAs have been recently identified [7, 9]. Interestingly, important biological effects of some FAHFAs have been reported. In particular, 5-PAHSA and 9-PAHSA have been shown to have anti-diabetic and anti-inflammatory activity in humans and rodents $[7,10]$. We have also recently reported that the long-term intake of 9-PAHPA or 9-OAHPA increased basal metabolism and insulin sensitivity in healthy mice fed a control diet [11]. However, there are still many questions about the biological roles of others FAHFAs in different physio-pathological states.

The objective of this work was to explore whether a longterm intake of 9-PAHPA or 9-OAHPA may induce similar effects in obesogenic diet-fed mice. To address this question, C57B16 mice were fed for 12 weeks with a high fathigh sugar (HFHS) diet supplemented with 9-PAHPA or 9-OAHPA and whole-body metabolism was explored with a particular focus on the liver functions as a key metabolic organ regarding insulin action, glucose production and its homeostatic control.

\section{Materials and methods}

\section{Animals and diets}

Forty 6-week-old male C57BL/6 J mice (Charles River, L'Arbresle, France), weighing about $22 \mathrm{~g}$, were housed (5 per cage) under conditions of constant temperature $\left(20-22{ }^{\circ} \mathrm{C}\right)$, humidity $(45-50 \%)$ and a standard dark cycle $(20.00-08.00 \mathrm{~h})$. The mice were randomized, according to their initial weight, into four groups of ten animals and fed for 12 weeks with one of the four following semi-purified diets: (1) control diet, (2) HFHS diet, (3) HFHS + 9-PAHPA, (4) HFHS + 9-OAHPA.

The detailed composition of the diets is given in the supplementary Table 1 . The control diet contains $5 \%$ lipids as a mixture of rapeseed oil, high oleic sunflower oil, sunflower oil and linseed oil (oil mixture of Carrefour), the HFHS diets contain $25 \%$ lipids ( $5 \%$ of a mixture of rapeseed oil, high oleic sunflower oil, sunflower oil and linseed oil and $20 \%$ of lard) and 30\% sucrose. The lipid fraction of the control diet was composed of $12.2 \%$ saturated fatty acids (SFA), $60.6 \%$ monounsaturated fatty acids (MUFA) and $27.3 \%$ polyunsaturated fatty acids (PUFA) and that of the HFHS diet was composed of $30.4 \%$ SFA, $53.4 \%$ MUFA and $16.3 \%$ PUFA (supplementary Table 2).

The 9-PAHPA (molecular mass $=510.5$ ) or the 9-OAHPA (molecular mass $=537$ ) was incorporated into the diet after dissolution in the combined table oils (oil mixture of Carrefour) and the final content of each FAHFA was set at $300 \mu \mathrm{mol} / \mathrm{kg}$ diet. For a mouse of $25 \mathrm{~g}$ that eats about $2.5 \mathrm{~g}$ diet/day, this corresponds to a FAHFA intake of about $30 \mu \mathrm{mol} / \mathrm{day} / \mathrm{kg}$ b.w. of mice (i.e., about $15 \mathrm{mg} / \mathrm{day} / \mathrm{kg}$ ). The administered dosage of the studied FAHFAs was based on the work of Yore et al. 2014 [7] as well as on the recent work of Paluchova et al. 2019 [12]. The synthesis of 9-PAHPA and 9-OAHPA was performed using our previously reported procedure [13].

Throughout the study, mice were given free access to tap water and to their respective diets. Mice body weight was followed weekly and food consumption was determined every 2 days (during the week) or 3 days (the week-end). Our institution guidelines for the care and use of laboratory animals were observed and all experimental procedures were approved by the local ethical committee in Montpellier, France (Reference APAFIS\#12759-2017121912214385). A detailed scheme of the study design is provided in Fig. 1.

\section{Body composition and metabolic analyses}

Mice whole-body composition (fat and lean masses) was measured every 2 weeks throughout the study using an EchoMRI-700 whole-body composition analyzer (Echo Medical Systems, Houston, TX), according to the manufacturer's instructions.

Oxygen consumption and carbon dioxide production were measured using a Comprehensive Lab Animal Monitoring System (CLAMS) (Columbus Instruments, Columbus, OH). Mice were housed in individual cage inside a controlled cabinet. Mice were acclimatized individually in metabolic cages at $22{ }^{\circ} \mathrm{C}$ with ad libitum access to food and water for 24-h, prior to a 24-h period of automated recordings. Sampled air from individual cages was passed through sensors to determine $\mathrm{O}_{2}$ and $\mathrm{CO}_{2}$ content. Sensors were calibrated 


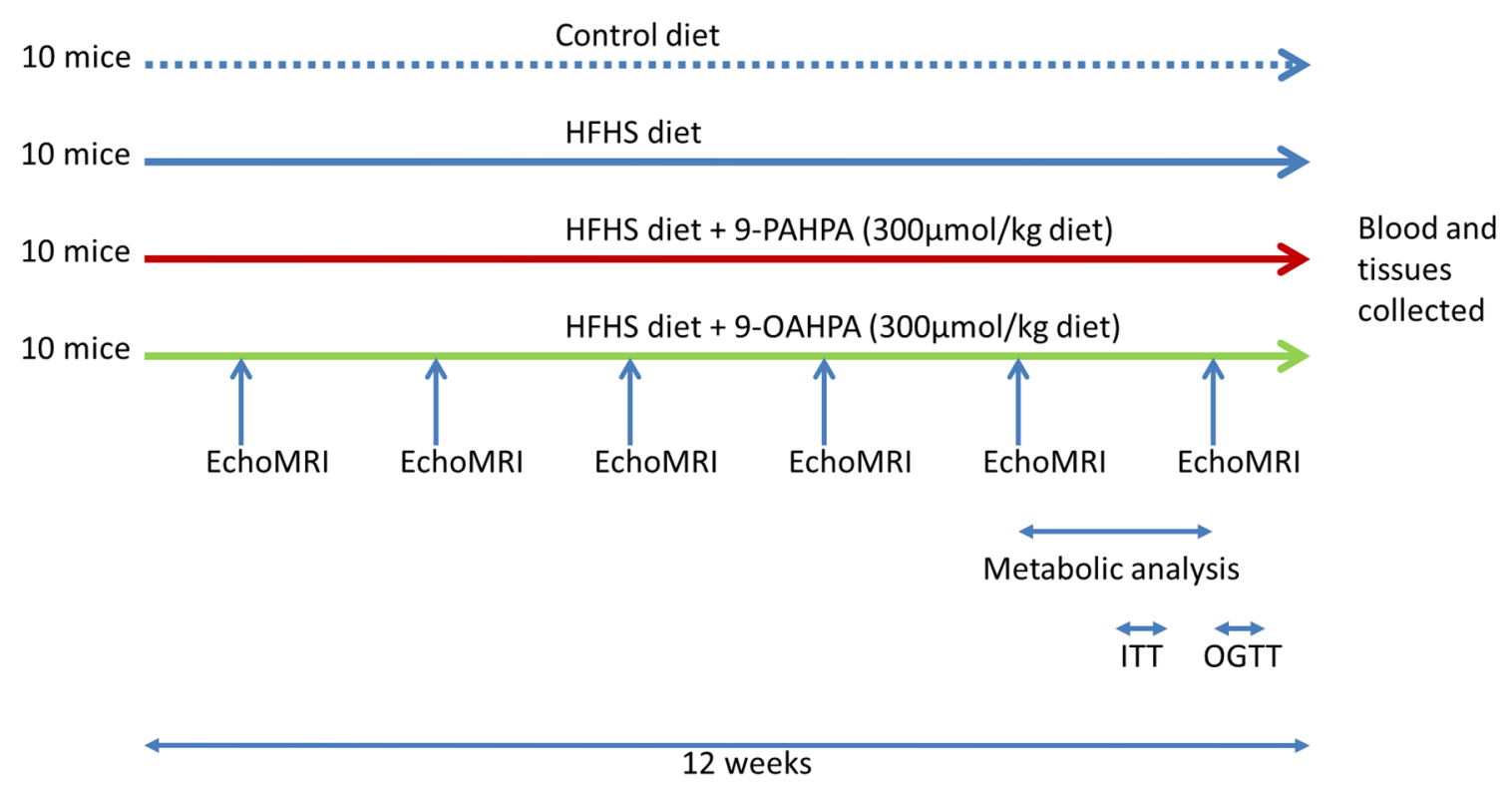

Fig. 1 Design of the study. Forty 6-week-old male C57BL/6 were fed for 12 weeks either a control diet, a high fat-high sucrose diet (HFHS), a HFHS diet+9-PAHPA or a HFHS diet+9-OAHPA. Whole body composition was measured every 2 weeks using an EchoMRI-700 analyzer. Mice oxygen consumption and carbon dioxide production were measured using a Comprehensive Lab Animal

before each experiment with commercial gas mixtures of accurately determined composition $(20.5 \% \mathrm{O} 2,0.5 \% \mathrm{CO} 2$ and $79 \% \mathrm{~N} 2)$. Volume of $\mathrm{O}_{2}\left(\mathrm{VO}_{2}\right)$ and $\mathrm{VCO}_{2}$ were measured 111 times in about $24 \mathrm{~h}$. The respiratory exchange ratio (RER) was calculated as the volume of $\mathrm{CO}_{2}$ vs. volume of $\mathrm{O}_{2}\left(\mathrm{VCO}_{2} / \mathrm{VO}_{2}\right)$ ratio [14].

\section{Oral glucose tolerance test (OGTT) and insulin tolerance test (ITT)}

Following an overnight fasting $(16 \mathrm{~h})$, mice were administrated glucose solution $(2 \mathrm{~g} / \mathrm{kg})$ by oral gavage, and blood were collected from the tail vein at the indicated times for glucose and insulin determination. Insulin tolerance was also assessed after $2 \mathrm{~h}$ fasting by administration of human insulin $(0.75 \mathrm{U} / \mathrm{kg})$ and blood glucose monitoring. Glycemia was measured using an OneTouch Verio glucometer (Lifescan).

\section{Sampling and routine biochemical analyses}

Four to five days after the OGTT or the ITT, blood from $12 \mathrm{~h}$-fasted mice was collected from the retro-orbital sinus and distributed into heparinized tubes. Blood tubes were centrifuged at $1000 \mathrm{~g}$ for $10 \mathrm{~min}$ at $4{ }^{\circ} \mathrm{C}$, plasma was collected and stored at $-80{ }^{\circ} \mathrm{C}$ until analysis. After cervical dislocation of mice, liver was removed, rinsed with $0.9 \%$ $\mathrm{NaCl}$, weighed, cut into several parts, plunged into liquid
Monitoring System the last weeks of the study. Oral glucose tolerance test and insulin tolerance test were performed the last weeks of the study. At the end of the study, blood was collected from retro-orbital sinus for biochemical analyses. After cervical dislocation, the liver was removed, rinsed, cut into several parts and frozen into liquid nitrogen until analyses

nitrogen and then kept at $-80{ }^{\circ} \mathrm{C}$ until analysis. In addition, liver fresh samples were frozen in Tissue-Tek (Microm Microtech) for histological analysis and stored at $-80{ }^{\circ} \mathrm{C}$. Moreover, white adipose tissue (WAT) was removed, rinsed with $0.9 \% \mathrm{NaCl}$ and kept at $-80{ }^{\circ} \mathrm{C}$ until analysis.

Plasma levels of glucose, total cholesterol, triglycerides and free fatty acids as well as enzymatic activity of alanine aminotransferase (ALT) were measured at the ANEXPLO/ CREFRE analysis platform (CHU RANGUEIL-BP 84225, France). Plasma levels of insulin, leptin and IL-6 were quantified with ELISA kits (Merck Millipore, Darmstadt, Germany; Crystal Chem, Zaandam, Netherlands; Abcam, Paris, France, respectively).

\section{Liver neutral lipids measurement and histological study}

Liver samples were homogenized in $\mathrm{NaCl}$ solution $(9 \mathrm{~g} / \mathrm{L})$ and Triton X-100 $(0.1 \%)$ and free fatty acids, triglycerides and total cholesterol levels were quantified on the tissue homogenate by enzymatic methods (Wako-NEFA-C kit, Oxoid, Dardilly, France; Cholesterol CHOD-PAP SOBIODA kit and triglycerides LQ SOBIODA kit, Sobioda 38330 Montbonnot-Saint-Martin, France) [15].

Histological liver analysis was performed on ten $\mu \mathrm{m}$ cryostat sections, stained with Oil Red O or Sirius Red. For Oil Red O staining, the sections were fixed in PBS, $4 \%$ 
paraformaldehyde at room temperature for $5 \mathrm{~min}$, washed in $\mathrm{H}_{2} \mathrm{O}$, incubated with $60 \%$ isopropanol for $5 \mathrm{~min}$ and then incubated in oil Red O solution $(0.6 \%)$ for $7 \mathrm{~min}$. The sections were then briefly washed with $60 \%$ isopropanol, incubated with Harris's Hematoxylin for $30 \mathrm{~s}$, washed in $\mathrm{H}_{2} \mathrm{O}$ for 3 min, and mounted.

For Sirius Red staining, the sections were fixed in PBS, 4\% PFA at room temperature $5 \mathrm{~min}$, washed in $\mathrm{H}_{2} \mathrm{O}$ and incubated in $0.01 \%$ Sirius Red F3B $1 \mathrm{~h}$. The sections were then washed twice in acidified water, dehydrated thrice in $100 \%$ ethanol, then cleared in xylene and mounted. For the morphometric analysis, liver sections were scanned using a NanoZoomer (Hamamatsu Photonics, Japan) with a 20 $\times$ objective. The degree of hepatic steatosis and liver fibrosis were, respectively, evaluated on Oil Red O and Sirius Red stained slides, and scored using Image $\mathbf{J}$ software as described [16].

\section{Liver oxidative stress status}

Liver samples were homogenized in phosphate buffer $(50 \mathrm{mM}, \mathrm{pH} 7) 1 \mathrm{~g}$ for $9 \mathrm{ml}$ buffer, using a Polytron homogenizer and long-established oxidative stress parameters were performed. The liver thiobarbituric acid reactive substances (TBARS) and total glutathione (GSH) levels were measured in homogenate according to the methods of Sunderman [17] and Griffith [18], respectively. The remaining homogenate was centrifuged at $1000 \mathrm{~g}$ for $10 \mathrm{~min}$ at $4{ }^{\circ} \mathrm{C}$ and the supernatant was used for the analyses of oxidative stress. Protein oxidation was assessed by measurement of thiol groups [19]. Catalase activity was measured according to the method of Beers and Sizer [20]. Glutathione peroxidase (GPx) was measured according to the method of Flohe and Gunzler [21]. Total superoxide dismutase (SOD) was measured according to the method of Marklund [22].

The liver isoprostanoid levels, considered as a reference method of lipid peroxidation, were measured based on micro-LC-MS/MS technique [23]. Briefly, after lipid extraction with Folch mixture, the extracts were mixed with a cocktail of internal standards, and an alkaline hydrolysis was performed. The metabolites were concentrated thanks to a solid phase extraction step conducted on weak-anion exchange materials. The metabolites were then analyzed by micro-LC-MS/MS. Mass spectrometry analysis was performed with an AB Sciex QTRAP5500 (Sciex Applied Biosystems), using electrospray in negative mode as the ionization source. Detection of the fragmentation ion products from each deprotonated molecule was performed in the multiple reaction monitoring modes. Metabolites quantification was done, using MultiQuant 3.0 software, by measuring the ratio of area under the specific metabolite peak/area under the internal standard peak and compared to the ratio of area under the metabolite calibration peak/area under the internal standard peak.

\section{Liver mitochondrial enzymatic activities}

The enzymatic activity of the different mitochondrial respiratory complexes was determined as previously described [24]. Citrate synthase (CS) activity was measured according to Srere [25]: the activity of the enzyme is measured by following the color of 5-thio-2-nitrobenzoic acid, which is generated from 5,5'-dithiobis-2-nitrobenzoic acid present in the reaction of citrate synthesis, and caused by the deacetylation of Acetyl-CoA. Complex I activity was measured spectrophotometrically at $600 \mathrm{~nm}$ during $45 \mathrm{~s}$ by following the reduction of 2,6-dichloroindophenol by electrons accepted from decylubiquinol, itself reduced after oxidation of NADH by complex I [26]. Complex II (CII) activity was measured spectrophotometrically at $600 \mathrm{~nm}$ by following the reduction of 2,6-dichloroindophenol by the succinate during $120 \mathrm{~s}$ [24]. Complex II + III (CII + CIII) activities were measured spectrophotometrically by following the oxidation of oxidation of cytochrome c at $550 \mathrm{~nm}$ during $90 \mathrm{~s}$ [27]. Cytochrome c oxidase (COX) activity was measured spectrophotometrically by following the oxidation of reduced cytochrome $\mathrm{c}$ at $550 \mathrm{~nm}$ during $30 \mathrm{~s}$ [28]. In addition, mitochondrial $\beta$-hydroxyacyl-CoA dehydrogenase ( $\beta$-HAD), a marker of last step of mitochondrial $\beta$-oxidation activity, was determined spectrophotometrically according to the procedure described by Clayton et al. [29].

\section{Protein isolation and western blotting analysis}

Frozen liver samples were homogenized using an Ultra Turax homogenizer in an ice cold extraction buffer containing $20 \mathrm{mM}$ Tris-HCL, $150 \mathrm{mM} \mathrm{NaCl}, 1 \mathrm{mM}$ EDTA, 0.5\% Triton X-100, 0.1\% SDS, 1 mM PMSF, $10 \mu \mathrm{M}$ leupeptin, and $1 \mu \mathrm{M}$ pepstatin. Proteins $(50 \mu \mathrm{g})$ were separated with 6-15\% SDS-PAGE and then transferred to a nitrocellulose membrane (120 min, $100 \mathrm{~V})$. Membranes were blocked in $5 \%$ fat-free milk for $1 \mathrm{~h}$ at room temperature. Then, membranes were incubated overnight with primary antibody against ChREBP, GLK, GLUT2, PEPCK, p-ACC, ACC, FAS, FATP4, PGC1 $\alpha$, L-CPT1, IL-6, and TNF- $\alpha$ in blocking buffer (See supplementary Table 3). After washes in TBS/Tween under gentle agitation, membranes were incubated for $1 \mathrm{~h}$ with horseradish peroxidase-labeled antibody. After further washes, blots were treated with enhanced chemiluminescence detection reagents (ThermoScientific, Illkirch, France). $\beta$-actin or $\alpha$-tubulin was used as loading references, and blot intensities were measured using Image Lab $^{\text {TM }}$ Software 5.2.1 (Bio-Rad Laboratories, Marnes-laCoquette, France). 


\section{Real-time quantitative RT-qPCR analysis}

Real-time Quantitative Polymerase Chain Reaction (RTqPCR) was used to measure target genes mRNA expression in liver. Total RNA was extracted with Trizol reagent (Invitrogen Life Technologies, Cergy Pontoise, France). Reverse transcription reaction was performed with $2 \mu \mathrm{g}$ total RNA. cDNA was synthesized with the use of PrimeScript RT reagent Kit (Perfect Real Time) (TAKARA) and Oligo (dT) primers + Randoms 6 mers. The mRNA expressions of target genes were determined by RT-qPCR, using a Step One Plus detection system (AB Applied Biosystems) and SYBR Premix Ex Taq II (TAKARA). Results were normalized with the gene encoding RPS9 used as the reference. The primer sequences used for real-time RT-PCR are given in the supplementary Table 4.

Real-time Quantitative Polymerase Chain Reaction (RTqPCR) was also applied to measure genes mRNA expression in the adipose tissue. RNA from WAT was extracted with Trizol reagent (Invitrogen Life Technologies, Cergy Pontoise, France). Reverse transcription reaction was performed with $1 \mu \mathrm{g}$ total RNA. cDNA was synthesized with the use of moloney murine leukemia virus reverse transcriptase for first strand cDNA synthesis and random primers. The mRNA expressions of target genes were determined by RTqPCR. RT-qPCR analysis was performed using SYBR Green Mastermix (Eurogentec, liege, Belgium) with a Mx3005P Real-Time PCR System (Stratagene, La Jolla, CA). Results were normalized with the gene encoding $18 \mathrm{~S}$. For the primer sequences used for real-time RT-PCR, see supplementary Table 4.

\section{Statistical analysis}

The number of mice required for this study was based on the expected difference in OGTT between the control and the HFHS groups. As the starting hypothesis was that the HFHS diet would increase the OGTT, we expected a $30 \%$ increase in OGTT in the HFHS group compared to the control group with a possible standard deviation of $20 \%$ of the higher mean value. Thus, for a type 1 risk $\alpha$ of 0.05 and a power (1- $\beta$ ) of $85 \%$, the number of mice required was 7 per group. However, because we have 4 experimental groups this study was designed with 10 mice/group.

Results were expressed as means \pm SD. HFHS diet vs. control diet was tested by a student $t$ test; ${ }^{*} p<0.05$ for HFHS vs. control diet. Inside the three HFHS diets, the effects of FAHFA intake was tested by a one-way ANOVA test, followed up by a Fisher's Least Significant Difference test. The means not sharing the same letter significantly differ. Correlations were performed with the Spearman method. The limit of statistical significance was set at $p<0.05$. Statistical analyses were performed using the StatView program (SAS Institute, Cary, NC, USA).

\section{Results}

\section{9-PAHPA and 9-OAHPA intake had no effect on obesity and hyperlipidemia induced by the HFHS diet}

We observed that mice mean food intake decreased in the HFHS diet-fed mice (Control: $2.79 \pm 0.06 \mathrm{~g} / \mathrm{mice} /$ day, HFHS: $2.55 \pm 0.13 \mathrm{~g} / \mathrm{mice} / \mathrm{day}$, HFHS + 9-PAHPA: $2.51 \pm 0.4 \mathrm{~g} / \mathrm{mice} /$ day, HFHS + 9-OAHPA: $2.72 \pm 0.12 \mathrm{~g} /$ mice/day). However, mice being housed 5 per cage, the sample size $(n=2)$ was too small to perform statistical analysis. The final body weight and fat mass, as well as lean mass, were significantly increased with the HFHS diet by comparison to controls. No specific effect of 9-PAHPA or 9-OAHPA intake was observed on any of these parameters. As expected, plasma leptin level was significantly increased in mice fed the HFHS diet, while plasma IL6 level was not modified (Fig. 2a). In addition, plasma triglycerides and total cholesterol levels were significantly increased with HFHS diet reflecting hyperlipidemia induced by this diet (Fig. 2a). However, no specific effect of 9-PAHPA or 9-OAHPA intake was observed on any of these parameters.

\section{9-PAHPA and/or 9-OAHPA intake modulated basal metabolism and carbohydrate oxidation}

Mice basal metabolism was investigated by measuring oxygen consumption $\left(\mathrm{VO}_{2}\right)$ and carbon dioxide production $\left(\mathrm{VCO}_{2}\right)$ using CLAMS system. $\mathrm{VO}_{2}$ reflecting the basal metabolism was significantly decreased with HFHS diet (Fig. 2b). Interestingly, while supplementation with 9-OAHPA had no impact on $\mathrm{VO}_{2}$, 9-PAHPA intake restored $\mathrm{VO}_{2}$ to control values. $\mathrm{VCO}_{2}$ was also significantly decreased with HFHS diet, while 9-PAHPA and 9-OAHPA intake limited this decreases (Fig. 2c). Moreover, HFHS diet significantly decreased RER $\left(\mathrm{VCO}_{2} / \mathrm{VO}_{2}\right)$ compared to the control diet, suggesting a higher preference for lipid oxidation (Fig. 2d). Interestingly, both 9-PAHPA and 9-OAHPA intake significantly increased RER by comparison to HFHS diet, thus favouring carbohydrate oxidation, however, without reaching the carbohydrate oxidation value obtained with the control diet (Fig. 2d). It is worth to notice that RER value was higher in mice supplemented with 9-OAHPA by comparison to 9-PAHPA (Fig. 2d). It should be pointed out that the HFHS phenotype obtained in this study was not extreme enough to unmask everything, explaining probably why FAHFAs has no marked effect on body weight and fat mass and non-significant change in food intake, 

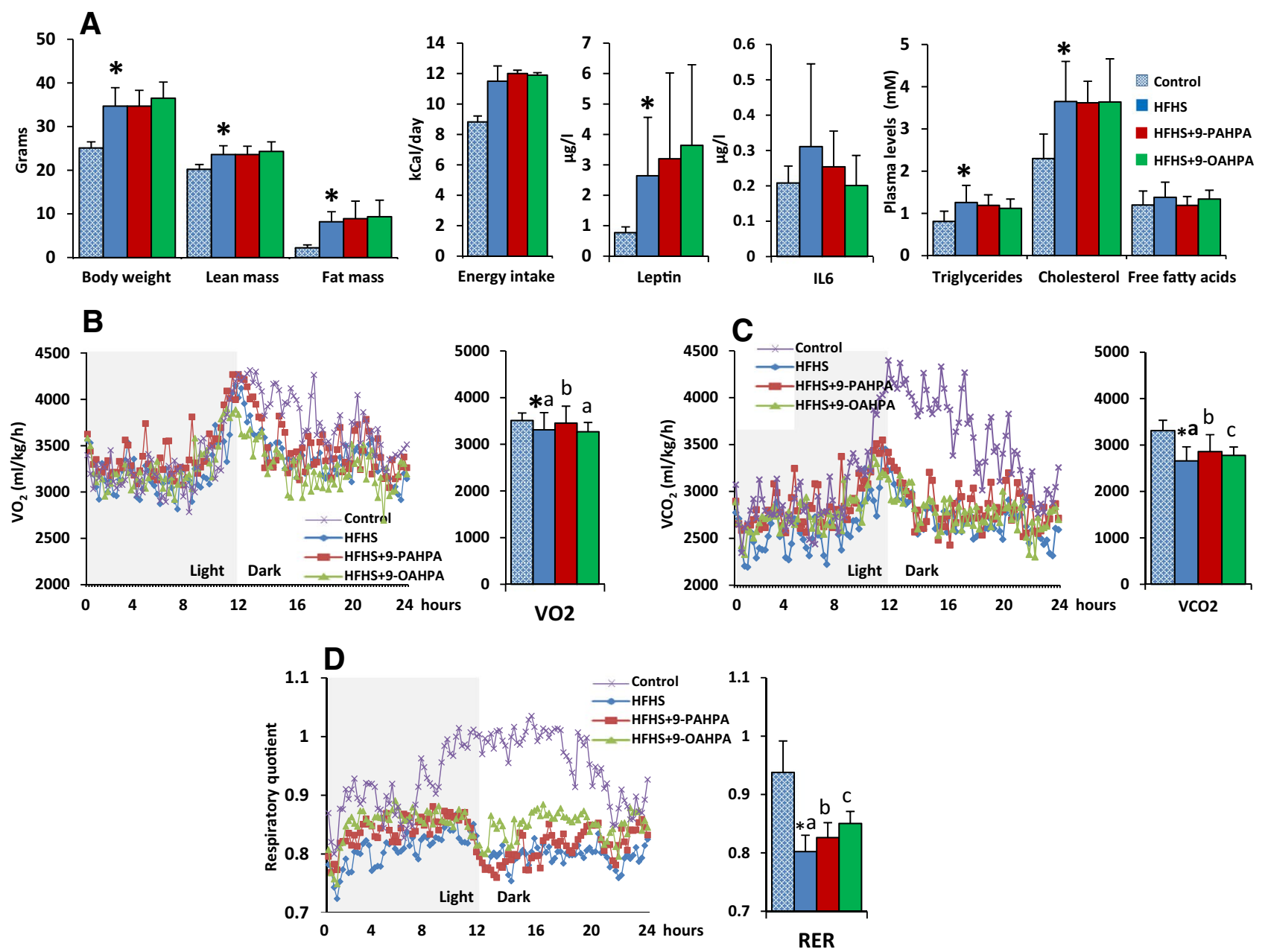

Fig. 2 Mice characteristics. a Body weight, lean and fat mass, plasma leptin and IL6, and circulating lipids, b oxygen consumption (VO2), c carbon dioxide consumption (VCO2) and $\mathbf{d}$ respiratory exchange ratio (RER) in mice. Results were expressed as means $\pm \mathrm{SD}, n=8-10$ animals per group. HFHS diet vs. control diet was tested by a student $t$ test; ${ }^{*} p<0.05$ for HFHS vs. control diet. Inside the three HFHS diets, the effects of FAHFA intake was tested by a one-way ANOVA test,

while energy expenditure is decreased. At least, it is possible that 9-PAHPA and 9-OAHPA exerted lipid remodeling/ futile substrate cycling burning energy as we have seen with 5-PAHSA [12].

\section{9-PAHPA and 9-OAHPA intake ameliorated peripheral insulin resistance but had no effect on glucose intolerance induced by HFHS diet}

Insulin tolerance test (ITT) reflects mainly insulin-stimulated peripheral utilization of glucose by tissues (in particular muscle) but also insulin ability to suppress (more or less completely) glucose production by the liver [30]. This test confirmed that HFHS diet induced insulin resistance in mice, and showed that both 9-PAHPA and 9-OAHPA intake followed up by a Fisher's Least Significant Difference test. The means not sharing the same letter significantly differ. The limit of statistical significance was set at $p<0.05$. For each mouse, VO2 and VCO2 were measured 111 times in about $24 \mathrm{~h}$. The respiratory exchange ratio (RER) was calculated as the volume of $\mathrm{CO} 2 \mathrm{vs}$. volume of oxygen $(\mathrm{VCO} 2 / \mathrm{VO} 2)$ ratio. Mean $\mathrm{VO} 2, \mathrm{VCO} 2$ and RER values are mean of 8 mice for each group considering all the cycles

increased insulin sensitivity in comparison to HFHS diet alone, yet without recovering the control values (Fig. 3a).

The oral glucose tolerance test (OGTT) is the reference method for the assessment of glucose tolerance [30]. It reflects the ability of the pancreas to secrete insulin and the responsiveness of the whole body in response to blood glucose levels. We observed that the HFHS diets, with or without 9-PAHPA or 9-OAHPA, rendered the mice diabetic as evidenced by the fasting hyperglycemia found in HFHS diet-fed mice (Fig. 3b). Nevertheless, neither 9-PAHPA nor 9-OAHPA showed any effect on glucose tolerance (Fig. 3b).

Fasted plasma glucose was increased with HFHS diet (Fig. 3c). In addition, insulin levels were up regulated with HFHS diet both in fast and in fed conditions (Fig. 3c) but no specific effect of 9-PAHPA or 9-OAHPA were observed 

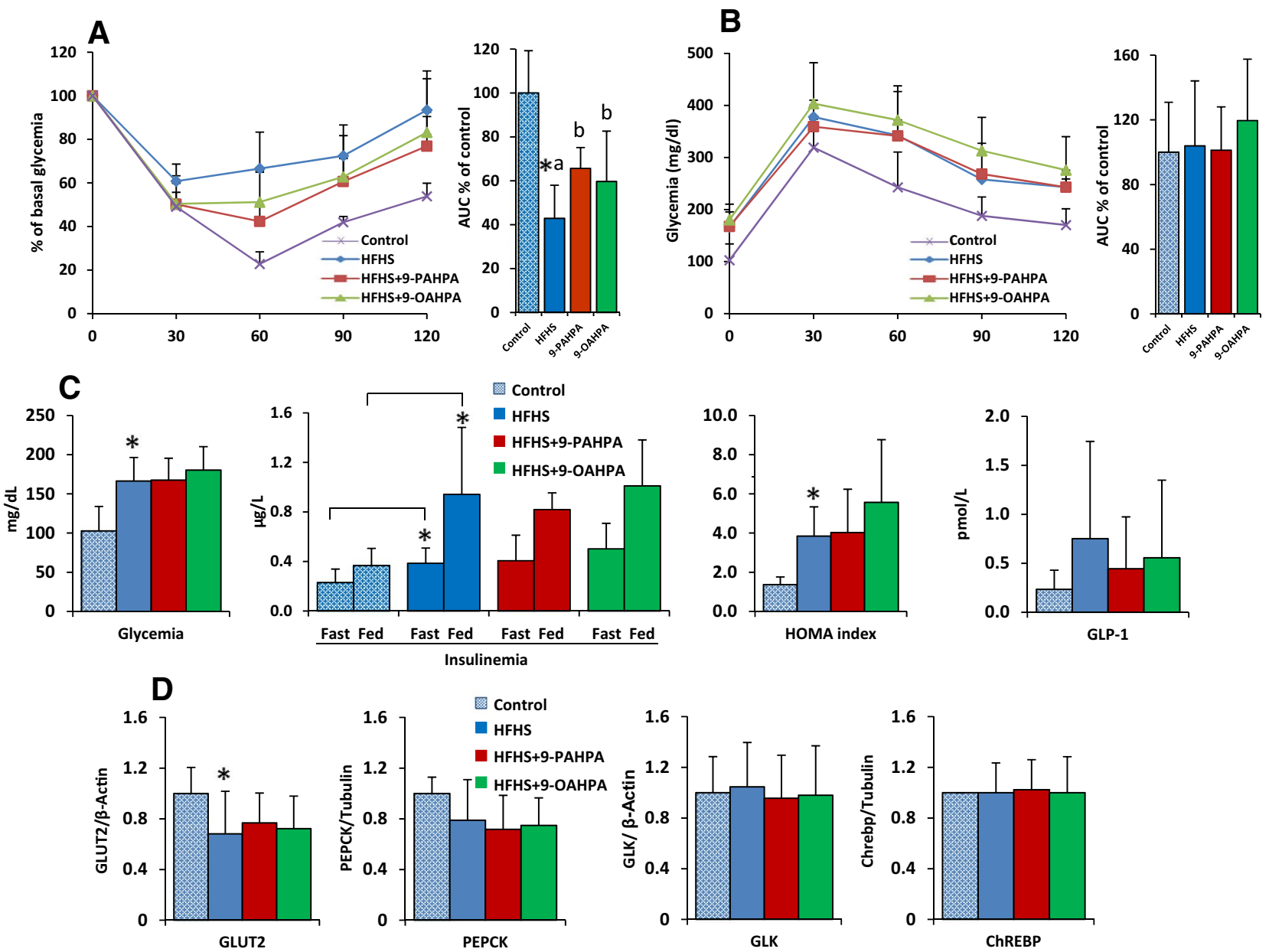

Fig. 3 Glucose and insulin parameters. a insulin tolerance test (ITT), b Glucose tolerance test (OGTT), c glycemia in fasted state and insulinemia in fasted or fed state (30 min glucose injection), HOMA index and plasma total GLP-1 level and d liver protein expression of markers of glucose metabolism. Results were expressed as means $\pm \mathrm{SD}, n=8-10$ animals per group. HFHS diet vs. control diet was tested by a student $t$ test; $* p<0.05$ for HFHS vs. control diet.

by comparison to HFHS alone. Moreover, HOMA index, reflecting mainly hepatic insulin resistance [30], was significantly increased with HFHS diet compared to controls. Surprisingly, no specific effects of 9-PAHPA or 9-OAHPA intake were observed on any of these parameters, suggesting increased peripheral utilization of glucose with these FAHFAs but no modification of liver glucose production or pancreas insulin secretion. Fasting level of plasma total GLP-1, an incretin promoting insulin secretion, was not modified whatever the diet (Fig. 3c), but was, however, positively correlated with fasted plasma insulin level $(r=0.520$, $p=0.0038$ ). Regarding the abundance of proteins involved in the glucose metabolism, liver expression of glucose transporter GLUT2 was decreased with the HFHS diet, while the expression of phosphoenolpyruvate carboxykinase (PEPCK), a key enzyme of gluconeogenesis, glucokinase

Inside the three HFHS diets, the effects of FAHFA intake was tested by a one-way ANOVA test, followed up by a Fisher's Least Significant Difference test. The means not sharing the same letter significantly differ. The limit of statistical significance was set at $p<0.05$. GLP-1: glucagon like peptide-1, GLUT2: glucose transporter 2, PEPCK: phosphoenol pyruvate kinase, GLK: glucokinase, ChREBP: carbohydrate-responsive element-binding protein

(GLK) and the glucose-activated transcription factor (CHREB) remained unchanged whatever the diet (Fig. 3d). No specific effect of 9-PAHPA or 9-OAHPA intake was observed on the expression of any of these proteins.

\section{9-PAHPA and 9-OAHPA intake had no effect on liver steatosis nor fibrosis}

Liver triglycerides, total cholesterol, free fatty acid and total lipid contents were measured in liver samples by colorimetric method. No modification was observed whatever the group of diets (Fig. 4b). Furthermore, histologic analysis revealed a slight increase in hepatic steatosis with the HFHS diet by comparison to controls. However, no significant impact of 9-PAHPA or 9-OAHPA intake was observed (Fig. 4c). However, it should be noticed that liver slices for 
A

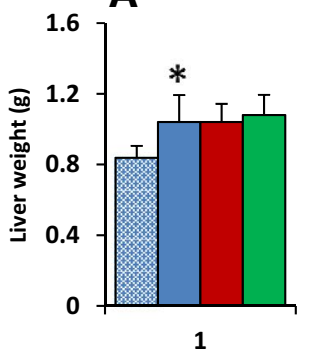

B

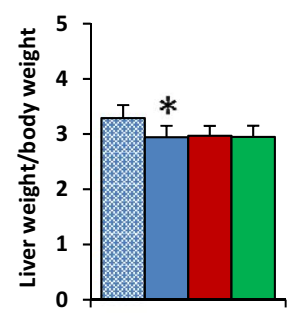

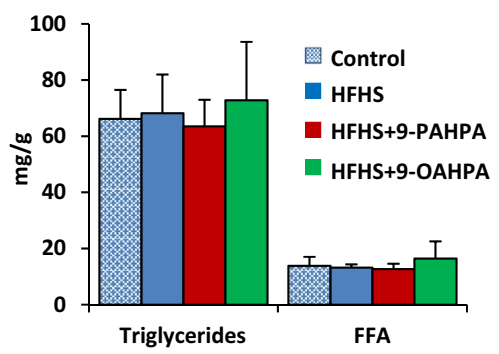
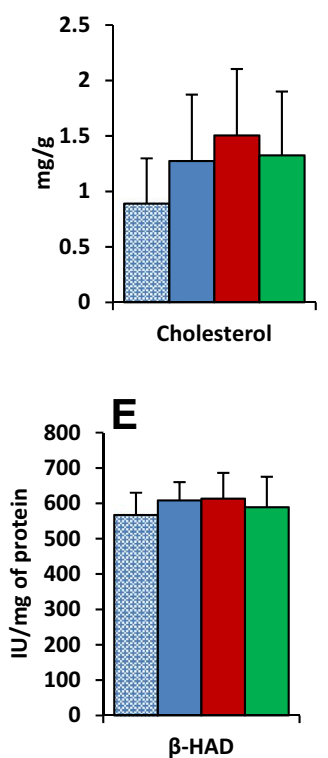

C

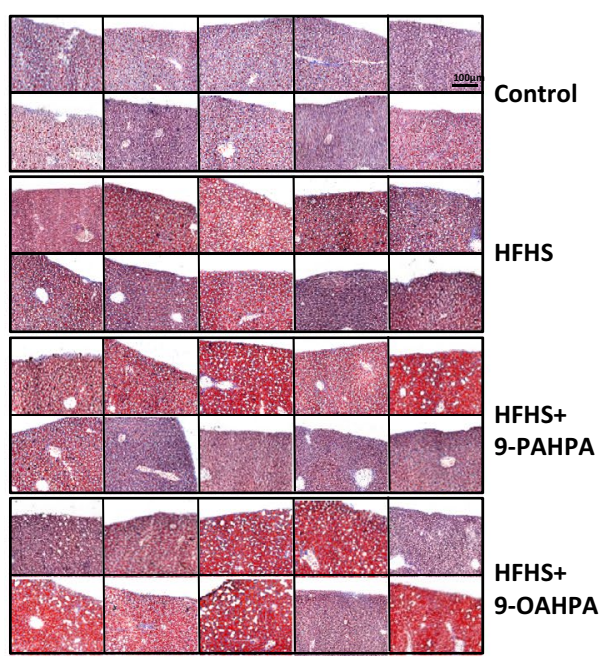

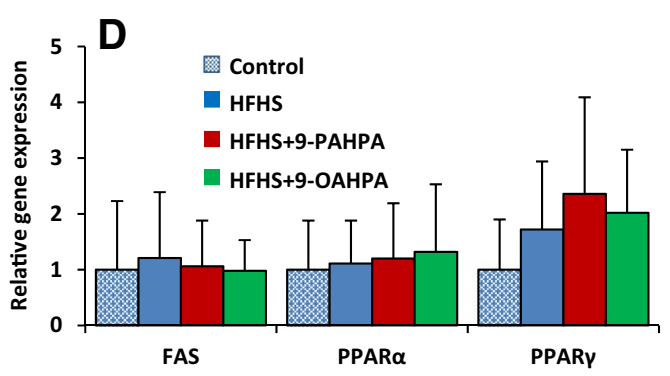

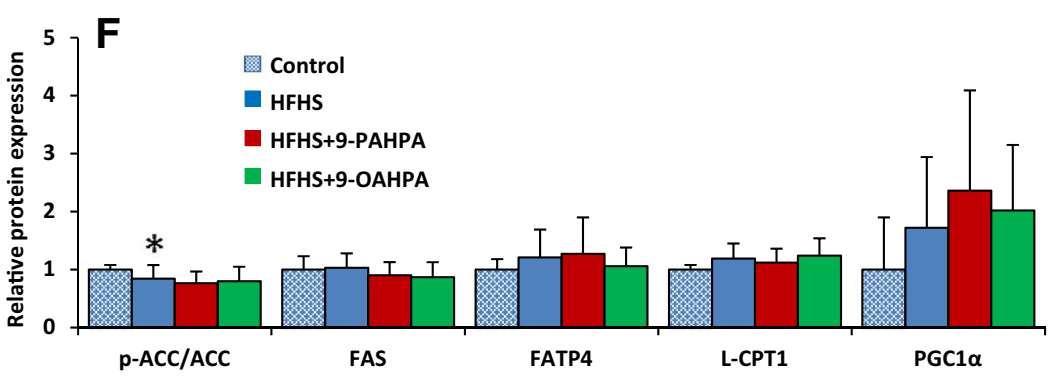

Fig. 4 Liver morphology and steatosis investigation. a Liver weight after 12 weeks of diet, $\mathbf{b}$ hepatic lipid content measured on tissue homogenate by enzymatic methods, c Oil red $\mathrm{O}$ staining of liver, pictures are representative from each group, d liver gene expression of key players in de novo lipogenesis, e liver $\beta$-HAD activity and $\mathbf{f}$ protein expression of key players in de novo lipogenesis. Results were expressed as means $\pm \mathrm{SD}, \mathrm{n}=9-10$ animals per group. HFHS diet vs. control diet was tested by a student $t$ test; ${ }^{*} p<0.05$ for HFHS vs control diet. Inside the three HFHS diets, the effects of

histological analysis were cut from the edge of the liver lobe and that such a sample is prone to smearing of lipid bodies [31, 32]. Accordingly, at necropsy macroscopical normal livers were observed independently of 9-PAHPA or 9-OAHPA intake (images not shown), a fatty liver was not recorded unlike to our previous observations with FAHFA supplementation of healthy mice [11]. In addition, liver gene expression of major players in hepatic de novo lipogenesis, fatty acid synthase (FAS) and peroxisome proliferator-activated receptors (PPAR) $\alpha$ and $\delta$, were unchanged whatever the diet (Fig. 4d). Moreover, liver protein expression of longchain fatty acid transport protein 4 (FATP-4), carnitine palmitoyltransferase I (L-CPT1), essential in the $\beta$-oxidation of long chain fatty acids, PGC1- $\alpha$, a master regulator of mitochondrial biogenesis, as liver 3-hydroxyacyl CoA
FAHFA intake was tested by a one-way ANOVA test, followed up by a Fisher's Least Significant Difference test. The means not sharing the same letter significantly differ. The limit of statistical significance was set at $p<0.05$. Representative Oil Red O (D) of livers from all the mice (magnification $\times 10$ ), $n=10$ animals per group. $\beta-H A D$ $\beta$-hydroxyacyl-CoA dehydrogenase, PPAR $\alpha$ peroxisome proliferatoractivated receptor alpha, $P P A R \gamma$ peroxisome proliferator-activated receptor gamma, ACC acetyl-CoA carboxylase, FAS/Fasn fatty acid synthase

dehydrogenase activity ( $\beta$-HAD), involved in $\beta$-oxidation remained unmodified whatever the diet (Fig. 4e). The p-ACC/ACC ratio (Acetyl-CoA carboxylase), involved in the biosynthesis of fatty acids was significantly decreased with the HFHS diet. However, 9-PAHPA or 9-OAHPA supplementation could not prevent these p-ACC/ACC ratios from decreasing (Fig. 4f).

Fibrosis was also investigated using Sirius red staining (Fig. 5a). Fibrosis in percentage, evaluated by analysis imagen was not modified with HFHS diet (Fig. 5b) and no significant impact of 9-PAHPA or 9-OAHPA intake was observed. Plasma ALAT activity, a biochemical marker of hepatic lysis/ fibrosis, was significantly increased with the HFHS diet, but with no significant effect of 9-PAHPA or 9-OAHPA intake (Fig. 5c). No modification of gene expression of major players 
A

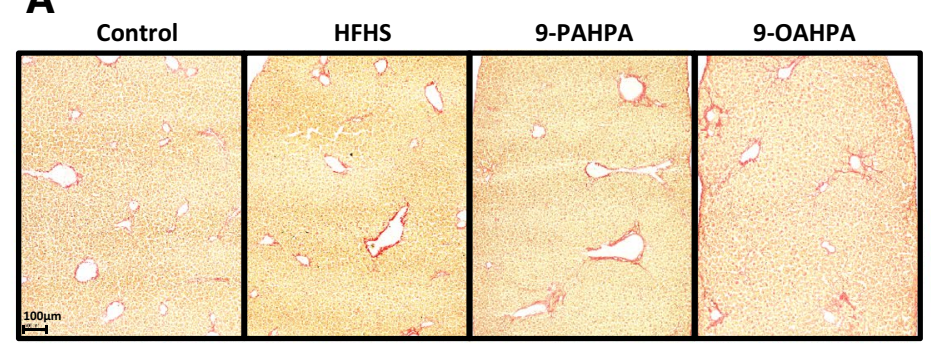

B

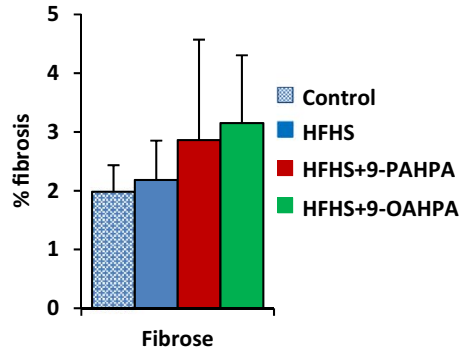

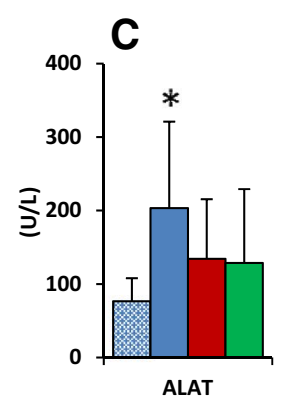
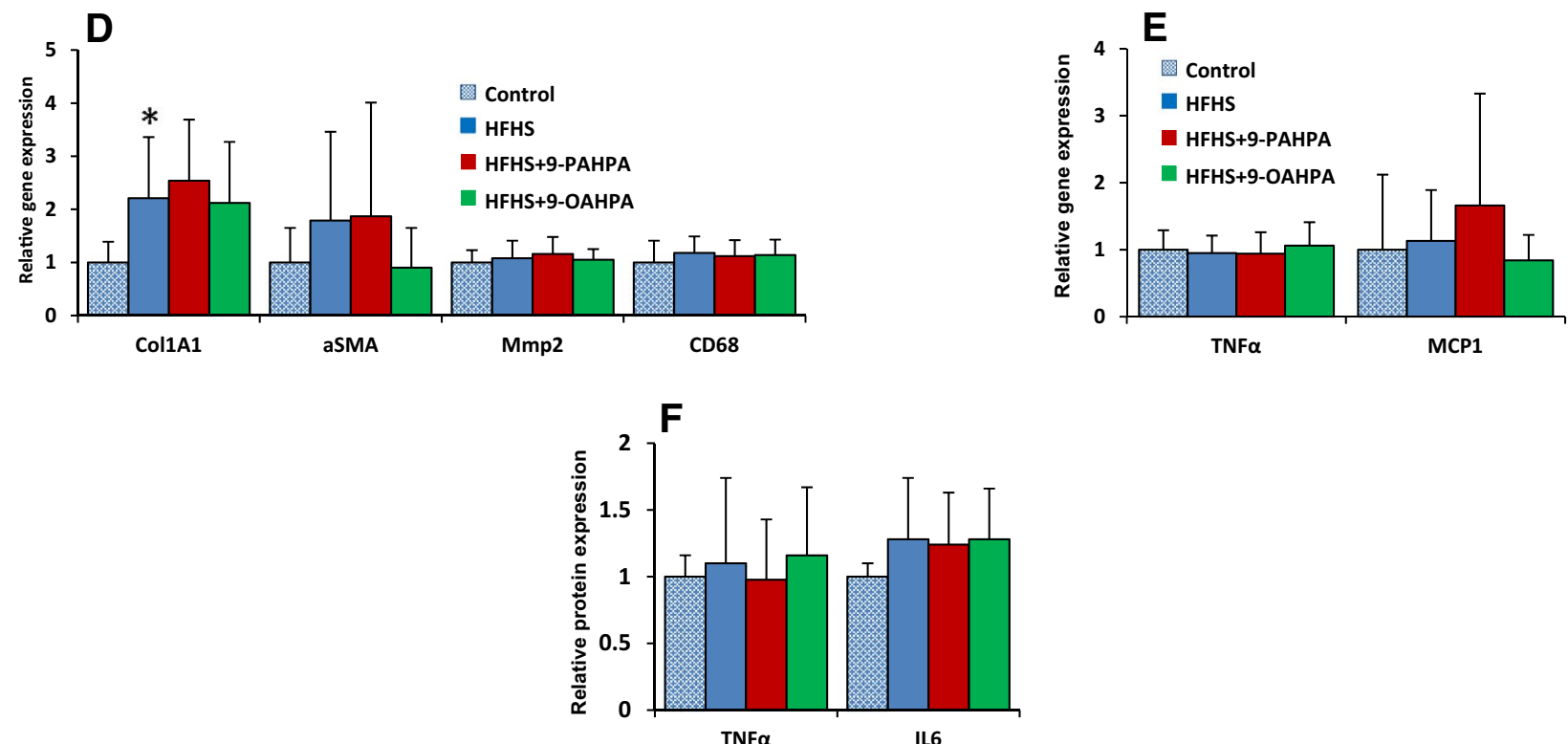

Fig. 5 Liver fibrosis investigation. a Sirius Red staining of liver, pictures are representative from each group (magnification $\times 10$ ). $\mathbf{b} \%$ of fibrosis and $\mathbf{c}$ plasma ALT activity. $\mathbf{d}$ Gene expression of liver fibrosis markers and e liver inflammation markers by qPCR. f Protein expression of TNF- $\alpha$ and IL- 6 by western blot and representative pictures from each group. Results were expressed as means $\pm \mathrm{SD}, n=9-10$ animals per group. HFHS diet vs. control diet was tested by a student $t$ test; ${ }^{*} p<0.05$ for HFHS vs. control diet. Inside the three HFHS diets, the effects of FAHFA intake was tested by a one-way ANOVA test, followed up by a Fisher's Least Significant Difference test. The means not sharing the same letter significantly differ. The limit of statistical significance was set at $p<0.05$. ALT alanine aminotransferase, CollA collagen type $\alpha 1$, aSMA a-smooth muscle actin, MMP2 matrix metalloproteinase-2, CD68 cluster of differentiation $68, T N F \alpha$ tumor necrosis factor $\alpha, M c p 1$ monocyte chemoattractant protein $1, I L-6$ interleukin 6 involved in liver fibrosis was observed whatever the group of diet, except for collagen Col1A1 that increased with the HFHS diet but without specific effect of 9-PAHPA or 9-OAHPA (Fig. 5d). All these results reflect little or no fibrosis with the HFHS diets.

Finally, no liver inflammation was observed as liver gene expression of TNF- $\alpha$ and MCP1 and liver protein expression of TNF- $\alpha$ and IL- 6 remained unchanged whatever the diet (Fig. 5e, f).

\section{9-PAHPA and 9-OAHPA intake had little effects on mitochondrial activity and liver oxidative stress alteration induced by HFHS diet}

Mitochondrial dysfunction and oxidative stress are interconnected and known to be involved in the development of steatosis to steatohepatitis and fibrosis [33]. No modification of mitochondrial respiratory chain complexes activity was observed with the HFHS diet (Fig. 6a). However, 

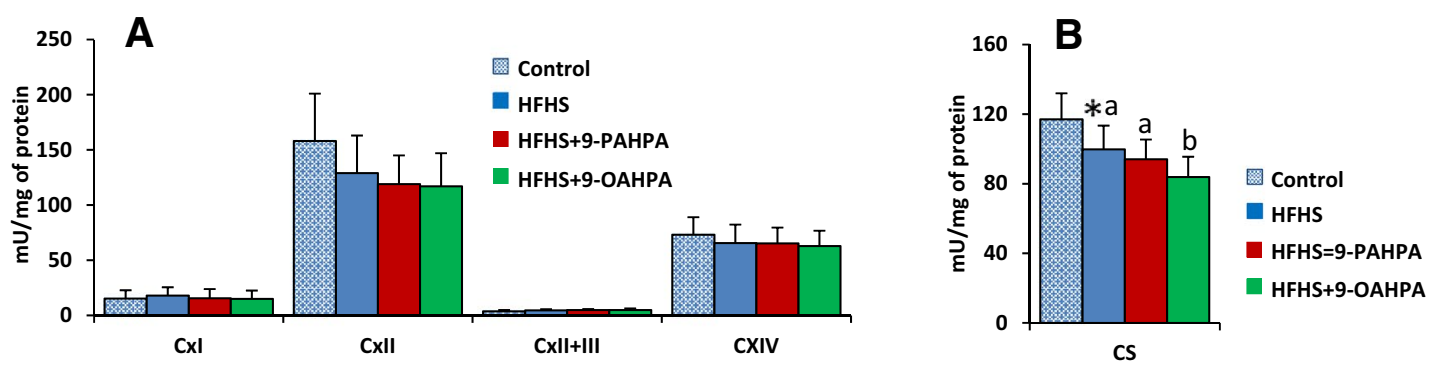

CS
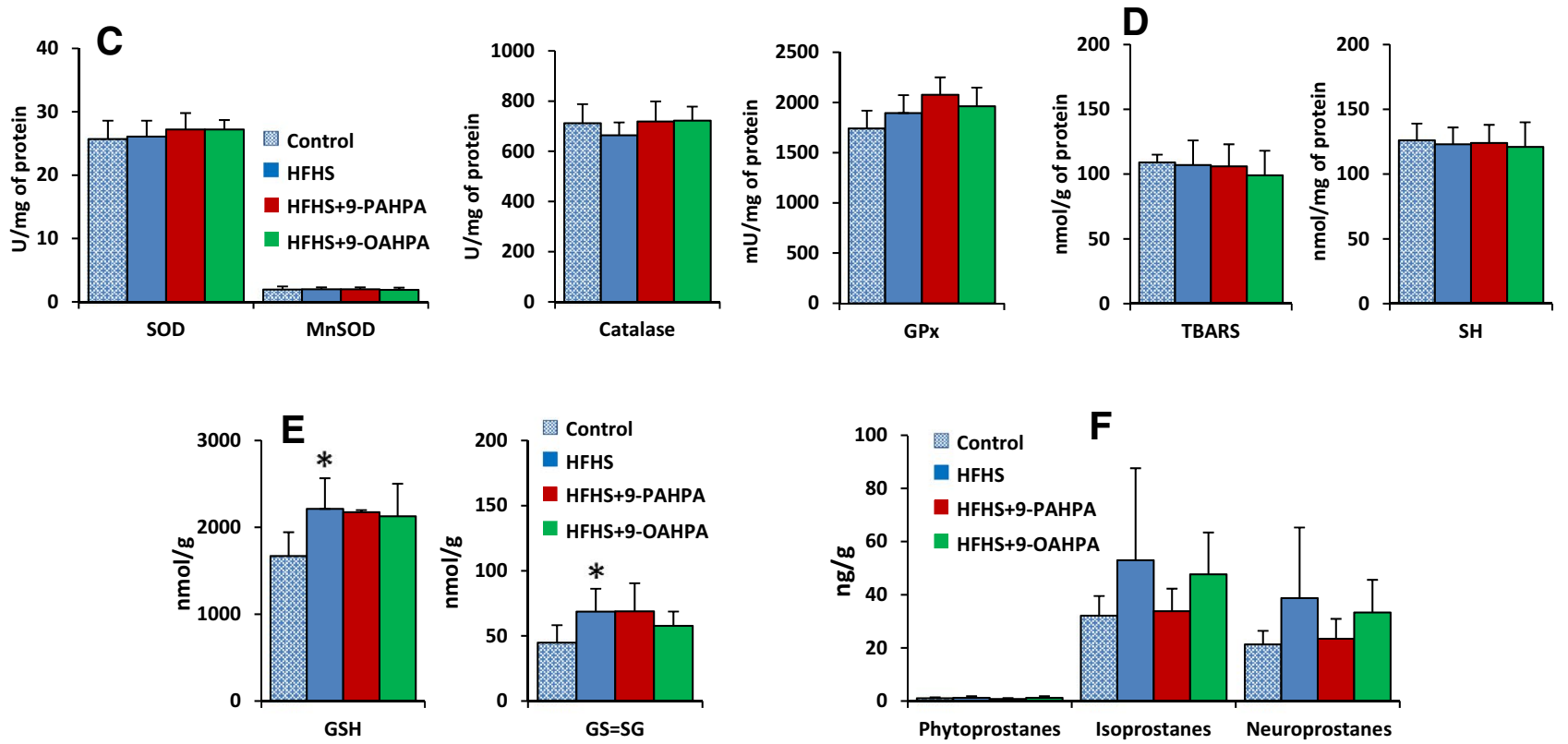

Fig. 6 Mitochondrial activity and hepatic oxidative stress parameters. a Mitochondrial respiratory chain activities. b Citrate synthase activity. c SOD, MnSOD, Catalase and GPx activities. d TBARS and -SH values. e GSH and GSSG values. f Phytoprostanes, Isoprostanes and Neuroprostanes values. Results were expressed as means \pm SD, $n=10$ animals per group. HFHS diet vs. control diet was tested by a student $t$ test; ${ }^{*} p<0.05$ for HFHS vs. control diet. Inside the three HFHS diets, the effects of FAHFA intake was tested by a one-way ANOVA test, followed up by a Fisher's Least Significant Difference test. The means not sharing the same letter significantly differ. The limit of statistical significance was set at $p<0.05$. CI complex I, CII complex

citrate synthase (CS), a marker of mitochondrial activity, was significantly decreased with the HFHS diet by comparison to control (Fig. 6b), most likely to limit de novo lipogenesis [34]. 9-PAHPA intake had no impact. However, 9-OAHPA intake significantly decreased liver CS activity by comparison to HFHS diet alone (Fig. 6b). Liver GSH and GSSG contents, but not GSH/GSSG ratio (data not shown) were increased with HFHS diet, with no significant effect of 9-PAHPA or 9-OAHPA (Fig. 6e). The other markers of oxidative stress measured in this study (antioxidant enzymes, oxidized lipids and proteins) were not modified with HFHS diets (Fig. 6c, d, f).

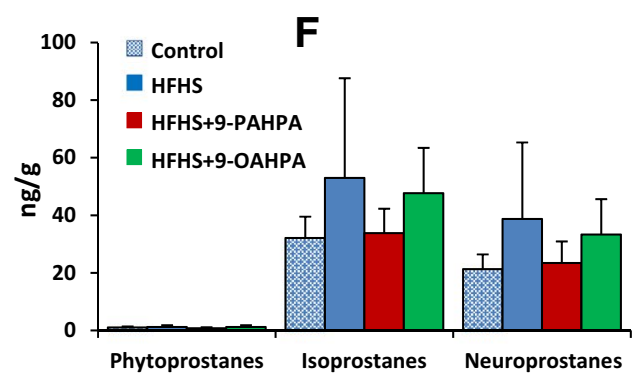

II, $C I I+I I I$ complexes II + III, $C O X$ cytochrome c oxidase, $C S$ citrate synthase, $S O D$ total superoxide dismutase, $M n S O D$ manganese superoxide dismutase, GPX glutathione peroxidase, TBARS thiobarbituric acid reactive substances, $-S H$ thiols, $G S H$ reduced glutathione, $G S S G$ oxidised glutathione, Phytoprostanes: ent-16- $\mathrm{B}_{1 \mathrm{t}}$-phytoprostane, ent-9- $\mathrm{L}_{1 \mathrm{t}}$-phytoprostane; Phytofuran: ent-16(RS)-13-epi-ST- $\Delta^{14}-9$ phytofuran; Isoprostanes: $15(S)-15-\mathrm{F}_{2 \mathrm{t}^{-}}$-isoprostane, $15(R)-15-\mathrm{F}_{2 \mathrm{t}^{-}}$ isoprostane, $5(R S)-5-\mathrm{F}_{2 \mathrm{t}}$-isoprostane, $5(R S)-5-\mathrm{F}_{2 \mathrm{c}}$-isoprostane; Neuroprostanes: $10(S)-10-\mathrm{F}_{4 \mathrm{t}}$-neuroprostane, $10(R)-10-\mathrm{F}_{4 \mathrm{t}}$-neuroprostane, $4(R S)-4-\mathrm{F}_{4 \mathrm{t}}$-neuroprostane

\section{9-OAHPA but not 9-PAHPA intake induced thermogenic phenotype in WAT}

Certain depots of WAT, in response to appropriate stimuli such as chronic cold exposure or certain pharmacologic treatments, undergo a process known as browning [35]. Gene expression of three markers of thermogenic fat cells, UCP1, PRDM16 and Cidea, was determined in epididymal WAT (Fig. 7a-c). UCP1 and Cidea gene expression were increased with HFHS diet with no significant effect of 9-PAHPA or 9-OAHPA (Fig. 7a, b). PRDM16 was not modified with the HFHS diet by comparison to controls but 

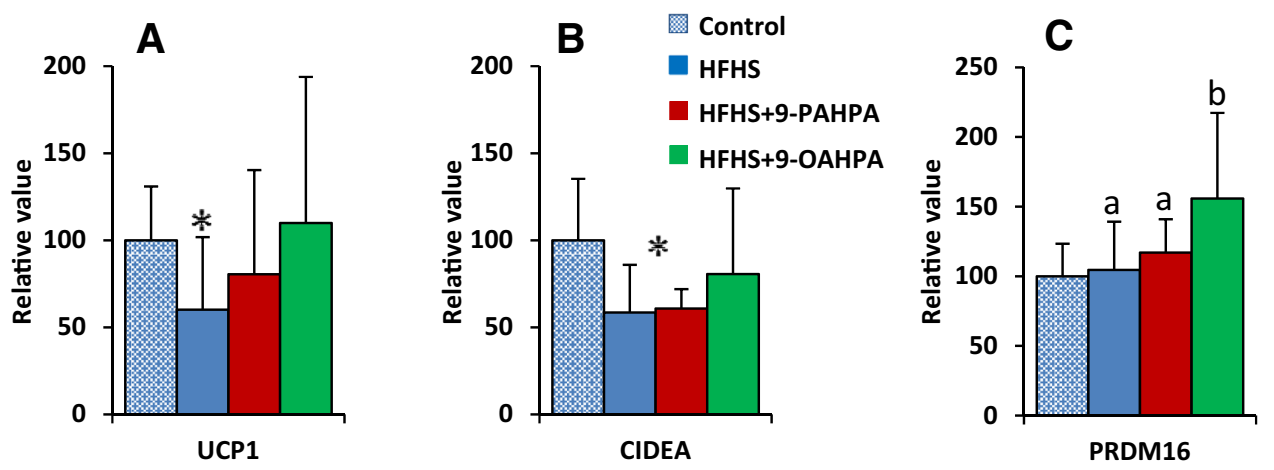

Fig. 7 Gene expression of markers of thermogenic fat cells in epididymal WAT by qPCR. Results were expressed as means \pm SD, $\mathrm{n}=9-10$ animals per group. HFHS diet vs. control diet was tested by a student $t$ test; $* p<0.05$ for HFHS vs control diet. Inside the three HFHS diets, the effects of FAHFA intake was tested by a one-

was significantly increased with 9-OAHPA while not with 9-PAHPA (Fig. 7c).

\section{Discussion}

The term "FAHFAs" has been introduced in 2014 for bioactive lipids found in adipocytes, with potential antidiabetic and anti-inflammatory properties [7, 8]. Branched FAHFAs are biosynthesized and stored in adipose tissue as nonesterified FAHFAs and FAHFA-containing triacylglycerols (FAHFAs-TG), FAHFA-TGs serving most likely as a storage form of FAHFAs under nutrient-rich conditions [12, 36]. FAHFAs were also detected in many others tissues $[7,8]$. To date, most of the saturated FAHFAs studied are branched regioisomers of Palmitic Acid Hydroxyl Stearic Acid (PAHSA) and nearly all of these studies indicated that both 5-PAHSA and 9-PAHSA may have anti-diabetic and anti-inflammatory activity in humans and rodents $[7,8,10]$. Yet, some disparate results have been recently reported, probably because of design differences in the experimental and analytical methodologies [37-39]. Some isomers of docosahexaenoic acid-derived fatty acid esters of hydroxy fatty acids and of linoleic acid acid-derived fatty acid esters of hydroxy fatty acids were also studied and it was observed that both 13(S)-DHAHLA and 13-LAHLA exerted antiinflammatory properties $[9,40]$. We have recently reported that other saturated branched FAHFAs may exhibit bioactive properties and insulin sensitizing effects. Indeed, long-term intake of 9-PAHPA or 9-OAHPA has been shown to increase basal metabolic rate and insulin sensitivity in healthy control diet-fed mice [39]. However, the insulin sensitizing effect of these specific FAHFAs was associated with slight adverse metabolic effects, as liver steatosis and fibrosis development in some of these mice. Regarding the great interest way ANOVA test, followed up by a Fisher's Least Significant Difference test. The means not sharing the same letter significantly differ. The limit of statistical significance was set at $p<0.05$. UCP1 uncoupling protein 1, CIDEA Cell death activator CIDE-A, PRDM16 PR domain-containing 16

of these issues in the obesity and diabetic states, whether a long-term intake of 9-PAHPA or 9-OAHPA may induce similar effects in obesogenic diet-fed mice was explored in the present study.

\section{9-PAHPA and 9-OAHPA intake modulated basal metabolic rate in obesogenic diet-fed mice}

Compared to the control mice, the HFHS diet-fed mice had higher calorie intake associated with a decrease in their basal metabolism. Accordingly, this positive energy balance resulted in an increased body weight and in obesity. Moreover, HFHS diet-fed mice exhibited lower respiratory exchange ratio (RER) than control mice, indicating a switch from carbohydrate to fat as the major energy source. In fact, a high RER suggests that carbohydrates are being predominantly utilized as source of fuel, whereas a low RER indicates fatty acid oxidation preference. Such an effect of HFHS diet has been already largely reported in the literature [41].

In a previous study, we reported that 9-PAHPA and 9-OAHPA intake increased basal metabolic rate in the healthy control diet-fed mice [11]. In the present study, the intake of 9-PAHPA but not the 9-OAHPA restored basal metabolism in the HFHS diet-fed mice to the level of control mice. It has been reported that increased energy expenditure contributes to body weight loss and protects against dietinduced obesity [42]. However, although its favorable effect on basal metabolism, 9-PAHPA intake did not modify body weight, fat mass and lean mass. This is in agreement with a recent report indicating that PAHSA treatment had no effect on body weight and fat mass [43]. Interestingly, 9-PAHPA or 9-OAHPA intake attenuated the preferential use of fatty acids over glucose as energy source observed in the HFHS diet-fed mice alone, as previously observed in healthy mice, and this effect was most pronounced with 9-OAHPA. The 
results indicate also that 9-PAHPA and 9-OAHPA modulate differently basal metabolism and substrates oxidation in HFHS diet-fed mice. To our knowledge, the effect of others FAHFAs on these parameters has not yet been reported. A tentative explanation may be find in the browning of white fat. Indeed, recent data indicate that some FAHFAs (from the PAHSAs family) can promote browning of white fat tissues [44] and it was shown that enhanced brown adipose tissue metabolic function could lead to increased oxygen consumption [45]. Interestingly, we observed that 9-OAHPA intake, but not that of 9-PAHPA, led to an increased PRDM16 gene expression, known as an inducer of thermogenic phenotype in fat cells [46].

\section{9-PAHPA and 9-OAHPA intake increased insulin sensitivity in obesogenic diet-fed mice}

Various methods exist to investigate glucose metabolism and insulin resistance, including the glucose and insulin tolerance tests, and the homeostasis model assessment (HOMA) index. Our present study indicated that the HFHS diet-fed mice developed hyperglycaemia and insulin resistance, and, therefore, diabetes, in line with the decreased RER observed in these mice. This observation was expected as the mouse model of diet-induced obesity is a well described model of obesity and insulin resistance [47]. However, intake of 9-PAHPA or 9-OAHPA did not prevent or protect from hyperglycemia and hyperinsulinemia observed with the HFHS diet. However, these both studied FAHFAs nicely increased insulin sensitivity as measured in ITT. The OGTT and ITT in this work do not assess the same aspect of carbohydrate homeostasis. While the OGTT reflects the ability of the pancreas to secrete insulin and the responsiveness of the whole body in response to high blood glucose levels, HOMA index reflects hepatic insulin resistance and ITT measures mainly insulin-stimulated peripheral utilization of glucose by muscle [30]. The pyruvate tolerance test (PTT) is also used to evaluate hepatic gluconeogenesis. However, this is an oversimplification as pyruvate is utilized by many other tissues. Analysis of neoglucogenesis with only PTT may make interpretation hazardous. Indeed, the optimal method to assess gluconeogenesis is the measurement of endogenous glucose fluxes with use of tracers. However, this involves the generation of a set of mice dedicated only to this experiment which is not possible because of the quantity of FAHFAs needed on the one hand and the number of additional animals which poses an ethical problem on the other hand. While exploring molecular glucose metabolism in the liver, we observed that HFHS diet altered the expression of the glucose transporter GLUT 2 but not of other proteins involved in glucose metabolism and we observed that neither 9-PAHPA nor 9-OAHPA had any impact on their expression. In healthy mice, we previously showed that glucose tolerance was not changed by any diet although intake of 9-PAHPA or 9-OAHPA nicely increased the insulin sensitivity too. A possible explanation may be that the innate glucose tolerance is satisfactory and sufficient in healthy mice [11].

The results obtained in the HFHS diet-fed mice may suggest that the insulin sensitizing effect of 9-PAHPA and 9-OAHPA may be exerted mainly on some peripheral tissues (skeletal muscle and heart). Zhou et al. [43] have recently reported that 5-PAHSA and 9-PAHSA enhance both hepatic and systemic insulin sensitivity. Moreover, 5-PAHSA and 9-PAHSA were previously shown to enhance glucose tolerance and insulin-sensitivity, insulin and GLP-1 secretion in chow- and high fat-diet fed mice, and to augment glucosestimulated insulin secretion in human islets from healthy or diabetic people [7, 48, 49].

\section{9-PAHPA and 9-OAHPA intake did not affect hepatic steatosis or fibrosis in obesogenic diet-fed mice}

Measurement of liver lipid content in HFHS diet-fed mice by biochemical methods did not show any difference with control mice for liver free fatty acids, cholesterol and triglycerides contents. Inflammation, mitochondrial dysfunction and oxidative stress were shown to be implicated in the progression of liver steatosis into steatohepatitis and fibrosis [50, 51]. However, no major change in plasma or liver inflammation marker was observed in mice fed with the HFHS diet. There was also no major change in mitochondrial or oxidative stress markers. Moreover, no fibrosis marker was modified with HFHS diet. It was previously shown that increased levels of liver triglycerides were only observed after 24 weeks of HFHS in mouse liver [41]. These observations support ours and confirm that the 12-week HFHS mice model is rather a model of diabetes than of liver steatosis, and that development of liver steatosis may require longer duration of HFHS diet at least in mouse [52].

We have recently demonstrated that long-term intake of 9-PAHPA or 9-OAHPA with a control diet induced liver steatosis and fibrosis in some healthy mice [11]. In the current study, the 9-PAHPA or 9-OAHPA intake seemed to increase liver steatosis, in some few mice fed the HFHS diet, as revealed by histological staining and visualization. However, this effect was not confirmed by biochemical analysis of lipid parameters and may rather result from smearing of lipid bodies in the slice from the edge of the liver lobe as this effect was not observed on whole liver. Moreover, minor fibrosis was observed with HFHS diet with no amplification by 9-PAHPA or 9-OAHPA intake, contrary to what was observed in the healthy mice fed the control diet. Indeed, the possible explanation for this difference if that in the present study the HFHS mice may have received a lower dose of 9-PAHPA or 9-OAHPA compared to the healthy mice 
fed the control diet in our previous study [11]. This may be due to a lower food intake from the HFHS diet and a lower distribution of FAHFA in these obese mice because of their higher body weight compared to the control mice. All these results indicate that 9-PAHPA or 9-OAHPA intake may have no major effects on liver when given with a HFHS diet, in the contrary to what we previously observed with the healthy mice fed the control diet [11]. Yet, these results also indicate no beneficial impact of these FAHFAs on liver metabolism. Few studies have reported the impact of others FAHFAs on liver lipid metabolism. In particular, it was shown that chronic 5-PAHSA and 9-PAHSA treatment had no impact on liver triglyceride levels in HFD-fed mice, despite improved hepatic insulin sensitivity [43] and that 5-PAHSA promoted fatty liver and inflammation in $\mathrm{db} / \mathrm{db}$ mice, a type 2 diabetes mouse model characterized by extreme hyperglycemia [53].

\section{Conclusion}

In this study, we showed that long-term intake of 9-PAHPA or 9-OAHPA modulated basal metabolism and had insulin sensitizing effect in obesogenic diet-fed mice. Interestingly, unlike what was observed in our previous study [11] on healthy control diet-fed mice supplemented with 9-OAHPA or 9-PAHPA, these FAHFAs had no major adverse effect on liver metabolism and homeostasis. Both 9-PAHPA and 9-OAHPA were given with the HFHS diet in initially non-obese animals to investigate their effect during the development of obesity and glucose/lipid metabolism perturbation. It would be interesting to explore their insulin-sensitizing effect in nutritionally or genetically animal models, where obese/insulin-resistance was already installed before 9-PAHPA and 9-OAHPA treatment.

Acknowledgements The authors thank Biocampus for animal staff from Metamus DMEM facility which belongs to RAM, Montpellier animal facilities network, for technical support and expertise for metabolism phenotyping, and for RHEM Facility for histology/immunohistology experiments. We acknowledge SIRIC Montpellier Cancer (Grant INCa_Inserm_DGOS_12553) to RHEM, and Metamontp platform supported by the European fund for the regional development of Occitanie (FEDER). The authors express their deep acknowledgements to Guillaume Reversat, Amandine Rocher and Camille Oger for their technical aid in the isoprostanoid analysis, Charlene Couturier for the WAT qPCR analysis and Annabelle Tavernier for the GLP-1 analysis.

Author contribution Author contributions were as follows: study design (CC, FC, CF-C), FAHFAs synthesis (LB, MB), data collection (MB, BB, LP, JG, GF, CV, SG, OK), statistical analysis (CC, MB, FC, CF-C), data interpretation (MB, CC, FC, FB, SG, OK, TD, LB, CF-C), manuscript preparation (MB, CC, OK, LB, FC, CF-C), literature search (MB, CC, FC, CF-C) and funds collection (CC, OK, FC, CF-C). All the authors have read and approved the final version of this manuscript.

Funding Melha Benlebna thanks the Algerian Ministry of Higher Education and Scientific Research for the financial support of her
$\mathrm{PhD}$ program. The authors also acknowledge the financial support of the French Lipid Nutrition Group, and the Czech Science Foundation (20-00317S). The authors are also grateful for the National Research Institute for Agriculture, Food and Environment (INRAE), in particular the Human Nutrition Department (Alim-H department) for their financial support.

\section{Compliance with ethical standards}

Conflict of interest The authors confirm that this article content has no conflict of interest.

\section{References}

1. Ng M, Fleming T, Robinson M, Thomson B, Graetz N, Margono C, Mullany EC, Biryukov S, Abbafati C, Abera SF, Abraham JP, Abu-Rmeileh NM, Achoki T, AlBuhairan FS, Alemu ZA, Alfonso R, Ali MK, Ali R, Guzman NA, Ammar W, Anwari P, Banerjee A, Barquera S, Basu S, Bennett DA, Bhutta Z, Blore J, Cabral N, Nonato IC, Chang JC, Chowdhury R, Courville KJ, Criqui MH, Cundiff DK, Dabhadkar KC, Dandona L, Davis A, Dayama A, Dharmaratne SD, Ding EL, Durrani AM, Esteghamati A, Farzadfar F, Fay DF, Feigin VL, Flaxman A, Forouzanfar MH, Goto A, Green MA, Gupta R, Hafezi-Nejad N, Hankey GJ, Harewood HC, Havmoeller R, Hay S, Hernandez L, Husseini A, Idrisov BT, Ikeda N, Islami F, Jahangir E, Jassal SK, Jee SH, Jeffreys M, Jonas JB, Kabagambe EK, Khalifa SE, Kengne AP, Khader YS, Khang YH, Kim D, Kimokoti RW, Kinge JM, Kokubo Y, Kosen S, Kwan G, Lai T, Leinsalu M, Li Y, Liang X, Liu S, Logroscino G, Lotufo PA, Lu Y, Ma J, Mainoo NK, Mensah GA, Merriman TR, Mokdad AH, Moschandreas J, Naghavi M, Naheed A, Nand D, Narayan KM, Nelson EL, Neuhouser ML, Nisar MI, Ohkubo T, Oti SO, Pedroza A, Prabhakaran D, Roy N, Sampson U, Seo H, Sepanlou SG, Shibuya K, Shiri R, Shiue I, Singh GM, Singh JA, Skirbekk V, Stapelberg NJ, Sturua L, Sykes BL, Tobias M, Tran BX, Trasande L, Toyoshima H, van de Vijver S, Vasankari TJ, Veerman JL, Velasquez-Melendez G, Vlassov VV, Vollset SE, Vos T, Wang C, Wang X, Weiderpass E, Werdecker A, Wright JL, Yang YC, Yatsuya H, Yoon J, Yoon SJ, Zhao Y, Zhou M, Zhu S, Lopez AD, Murray CJ, Gakidou E (2014) Global, regional, and national prevalence of overweight and obesity in children and adults during 1980-2013: a systematic analysis for the Global Burden of Disease Study 2013. Lancet 384(9945):766-781. https ://doi.org/10.1016/S0140-6736(14)60460-8

2. Alberti KG, Zimmet P, Shaw J, Group IDFETFC (2005) The metabolic syndrome-a new worldwide definition. Lancet 366(9491):1059-1062. https://doi.org/10.1016/S0140 $-6736(05) 67402-8$

3. Saeedi P, Petersohn I, Salpea P, Malanda B, Karuranga S, Unwin N, Colagiuri S, Guariguata L, Motala AA, Ogurtsova K, Shaw JE, Bright D, Williams R, Committee IDFDA (2019) Global and regional diabetes prevalence estimates for 2019 and projections for 2030 and 2045: Results from the International Diabetes Federation Diabetes Atlas, 9(th) edition. Diabetes Res Clin Pract 157:107843. https://doi.org/10.1016/j.diabres.2019.107843

4. Williams R, Karuranga S, Malanda B, Saeedi P, Basit A, Besancon S, Bommer C, Esteghamati A, Ogurtsova K, Zhang P, Colagiuri S (2020) Global and regional estimates and projections of diabetes-related health expenditure: results from the International Diabetes Federation Diabetes Atlas, edition. Diabetes Res Clin Pract 162:108072. https://doi.org/10.1016/j.diabres.2020.108072

5. Kim KH, Lee MS (2018) Pathogenesis of nonalcoholic steatohepatitis and hormone-based therapeutic approaches. Front 
Endocrinol (Lausanne) 9:485. https://doi.org/10.3389/fendo 2018.00485

6. Angulo P (2002) Nonalcoholic fatty liver disease. N Engl J Med 346(16):1221-1231. https://doi.org/10.1056/NEJMra011775

7. Yore MM, Syed I, Moraes-Vieira PM, Zhang T, Herman MA, Homan EA, Patel RT, Lee J, Chen S, Peroni OD, Dhaneshwar AS, Hammarstedt A, Smith U, McGraw TE, Saghatelian A, Kahn BB (2014) Discovery of a class of endogenous mammalian lipids with anti-diabetic and anti-inflammatory effects. Cell 159(2):318-332. https://doi.org/10.1016/j.cell.2014.09.035

8. Balas L, Feillet-Coudray C, Durand T (2018) Branched fatty acyl esters of hydroxyl fatty acids (FAHFAs), appealing beneficial endogenous fat against obesity and type-2 diabetes. Chemistry 24(38):9463-9476. https://doi.org/10.1002/chem.201800853

9. Kuda O, Brezinova M, Rombaldova M, Slavikova B, Posta M, Beier P, Janovska P, Veleba J, Kopecky J Jr, Kudova E, Pelikanova T, Kopecky J (2016) Docosahexaenoic acid-derived fatty acid esters of hydroxy fatty acids (FAHFAs) with anti-inflammatory properties. Diabetes 65(9):2580-2590. https://doi.org/10.2337/ db16-0385

10. Bandak B, Yi L, Roper MG (2018) Microfluidic-enabled quantitative measurements of insulin release dynamics from single islets of Langerhans in response to 5-palmitic acid hydroxy stearic acid. Lab Chip 18(18):2873-2882. https://doi.org/10.1039/c81c00624e

11. Benlebna M, Balas L, Bonafos B, Pessemesse L, Vigor C, Grober J, Bernex F, Fouret G, Paluchova V, Gaillet S, Landrier JF, Kuda O, Durand T, Coudray C, Casas F, Feillet-Coudray C (2020) Long-term high intake of 9-PAHPA or 9-OAHPA increases basal metabolism and insulin sensitivity but disrupts liver homeostasis in healthy mice. J Nutr Biochem 79:108361. https://doi. org/10.1016/j.jnutbio.2020.108361

12. Paluchova V, Oseeva M, Brezinova M, Cajka T, Bardova K, Adamcova K, Zacek P, Brejchova K, Balas L, Chodounska H, Kudova E, Schreiber R, Zechner R, Durand T, Rossmeisl M, Abumrad NA, Kopecky J, Kuda O (2020) Lipokine 5-PAHSA is regulated by adipose triglyceride lipase and primes adipocytes for de novo lipogenesis in mice. Diabetes 69(3):300-312. https://doi. org/10.2337/db19-0494

13. Balas L, Bertrand-Michel J, Viars F, Faugere J, Lefort C, CasparBauguil S, Langin D, Durand T (2016) Regiocontrolled syntheses of FAHFAs and LC-MS/MS differentiation of regioisomers. Org Biomol Chem 14(38):9012-9020. https://doi.org/10.1039/c6ob0 $1597 b$

14. Marvyn PM, Bradley RM, Mardian EB, Marks KA, Duncan RE (2016) Data on oxygen consumption rate, respiratory exchange ratio, and movement in $\mathrm{C} 57 \mathrm{BL} / 6 \mathrm{~J}$ female mice on the third day of consuming a high-fat diet. Data Brief 7:472-475. https://doi. org/10.1016/j.dib.2016.02.066

15. Coudray C, Fouret G, Lambert K, Ferreri C, Rieusset J, BlachnioZabielska A, Lecomte J, Ebabe Elle R, Badia E, Murphy MP, Feillet-Coudray C (2016) A mitochondrial-targeted ubiquinone modulates muscle lipid profile and improves mitochondrial respiration in obesogenic diet-fed rats. Br J Nutr 115(7):1155-1166. https://doi.org/10.1017/S0007114515005528

16. Standish RA, Cholongitas E, Dhillon A, Burroughs AK, Dhillon AP (2006) An appraisal of the histopathological assessment of liver fibrosis. Gut 55(4):569-578. https://doi.org/10.1136/ gut.2005.084475

17. Sunderman FW Jr, Marzouk A, Hopfer SM, Zaharia O, Reid MC (1985) Increased lipid peroxidation in tissues of nickel chloridetreated rats. Ann Clin Lab Sci 15(3):229-236

18. Griffith OW (1980) Determination of glutathione and glutathione disulfide using glutathione reductase and 2-vinylpyridine. Anal Biochem 106(1):207-212. https://doi.org/10.1016/00032697(80)90139-6
19. Faure P, Lafond J (1995) Measurement of plasma sulfhydryl and carbonyl groups as a possible indicator of protein oxidation. In: Favier A, Cadet J, Kalyanaraman B, Fontecave M, Pierre J (eds) Analysis of Free Radicals in Biological Systems. Birkhauser Verlag Basel, Switzerland, pp 237-248

20. Beers RF Jr, Sizer IW (1952) A spectrophotometric method for measuring the breakdown of hydrogen peroxide by catalase. J Biol Chem 195(1):133-140

21. Flohe L, Gunzler WA (1984) Assays of glutathione peroxidase. Methods Enzymol 105:114-121. https://doi.org/10.1016/s0076 $-6879(84) 05015-1$

22. Marklund S (1976) Spectrophotometric study of spontaneous disproportionation of superoxide anion radical and sensitive direct assay for superoxide dismutase. J Biol Chem 251(23):7504-7507

23. Dupuy A, Le Faouder P, Vigor C, Oger C, Galano JM, Dray C, Lee JC, Valet P, Gladine C, Durand T, Bertrand-Michel J (2016) Simultaneous quantitative profiling of 20 isoprostanoids from omega- 3 and omega- 6 polyunsaturated fatty acids by LC-MS/MS in various biological samples. Anal Chim Acta 921:46-58. https ://doi.org/10.1016/j.aca.2016.03.024

24. Feillet-Coudray C, Sutra T, Fouret G, Ramos J, Wrutniak-Cabello C, Cabello G, Cristol JP, Coudray C (2009) Oxidative stress in rats fed a high-fat high-sucrose diet and preventive effect of polyphenols: involvement of mitochondrial and NAD $(\mathrm{P}) \mathrm{H}$ oxidase systems. Free Radic Biol Med 46(5):624-632

25. Srere P (1969) Citrate synthase. Methods Enzymol 13:3-11

26. Janssen AJ, Trijbels FJ, Sengers RC, Smeitink JA, van den Heuvel LP, Wintjes LT, Stoltenborg-Hogenkamp BJ, Rodenburg RJ (2007) Spectrophotometric assay for complex I of the respiratory chain in tissue samples and cultured fibroblasts. Clin Chem 53(4):729-734. https://doi.org/10.1373/clinchem.2006.078873

27. Rustin P, Chretien D, Bourgeron T, Gerard B, Rotig A, Saudubray JM, Munnich A (1994) Biochemical and molecular investigations in respiratory chain deficiencies. Clin Chim Acta 228(1):35-51. https://doi.org/10.1016/0009-8981(94)90055-8

28. Wharton D, Tzagoloff A (1967) Cytochrome oxidase from beef heart mitochondria. Methods Enzymol 10:245-250

29. Clayton PT, Eaton S, Aynsley-Green A, Edginton M, Hussain K, Krywawych S, Datta V, Malingre HE, Berger R, van den Berg IE (2001) Hyperinsulinism in short-chain L-3-hydroxyacyl-CoA dehydrogenase deficiency reveals the importance of beta-oxidation in insulin secretion. J Clin Invest 108(3):457-465. https://doi. org/10.1172/JCI11294

30. Rabasa-Lhoret R, Laville M (2001) How to measure insulin sensitivity in clinical practice? Diabetes Metab 27(2 Pt 2):201-208

31. Levene AP, Kudo H, Armstrong MJ, Thursz MR, Gedroyc WM, Anstee QM, Goldin RD (2012) Quantifying hepatic steatosismore than meets the eye. Histopathology 60(6):971-981. https:// doi.org/10.1111/j.1365-2559.2012.04193.x

32. Gerspach C, Imhasly S, Klingler R, Hilbe M, Hartnack S, Ruetten M (2017) Variation in fat content between liver lobes and comparison with histopathological scores in dairy cows with fatty liver. BMC Vet Res 13(1):98. https://doi.org/10.1186/s1291 7-017-1004-9

33. Manne V, Handa P, Kowdley KV (2018) Pathophysiology of nonalcoholic fatty liver disease/nonalcoholic steatohepatitis. Clin Liver Dis 22(1):23-37. https://doi.org/10.1016/j.cld.2017.08.007

34. Ferramosca A, Conte A, Damiano F, Siculella L, Zara V (2014) Differential effects of high-carbohydrate and high-fat diets on hepatic lipogenesis in rats. Eur J Nutr 53(4):1103-1114. https:// doi.org/10.1007/s00394-013-0613-8

35. Lim J, Park HS, Kim J, Jang YJ, Kim JH, Lee Y, Heo Y (2020) Depot-specific UCP1 expression in human white adipose tissue and its association with obesity-related markers. Int J Obes (Lond) 44(3):697-706. https://doi.org/10.1038/s41366-020-0528-4 
36. Tan D, Ertunc ME, Konduri S, Zhang J, Pinto AM, Chu Q, Kahn BB, Siegel D, Saghatelian A (2019) Discovery of FAHFAcontaining triacylglycerols and their metabolic regulation. J Am Chem Soc 141(22):8798-8806. https://doi.org/10.1021/jacs.9b000 45

37. Pflimlin E, Bielohuby M, Korn M, Breitschopf K, Lohn M, Wohlfart P, Konkar A, Podeschwa M, Barenz F, Pfenninger A, Schwahn U, Opatz T, Reimann M, Petry S, Tennagels N (2018) Acute and repeated treatment with 5-PAHSA or 9-PAHSA isomers does not improve glucose control in mice. Cell Metab 28(2):217-227.e213

38. Kuda O (2018) On the complexity of PAHSA research. Cell Metab 28(4):541-542. https://doi.org/10.1016/j.cmet.2018.09.006

39. Syed I, Lee J, Peroni OD, Yore MM, Moraes-Vieira PM, Santoro A, Wellenstein K, Smith U, McGraw TE, Saghatelian A, Kahn BB (2018) Methodological issues in studying PAHSA biology: masking PAHSA effects. Cell Metab 28(4):543-546. https://doi. org/10.1016/j.cmet.2018.09.007

40. Kolar MJ, Konduri S, Chang T, Wang H, McNerlin C, Ohlsson L, Harrod M, Siegel D, Saghatelian A (2019) Linoleic acid esters of hydroxy linoleic acids are anti-inflammatory lipids found in plants and mammals. J Biol Chem 294(27):10698-10707. https ://doi.org/10.1074/jbc.RA118.006956

41. Burchfield JG, Kebede MA, Meoli CC, Stockli J, Whitworth PT, Wright AL, Hoffman NJ, Minard AY, Ma X, Krycer JR, Nelson ME, Tan SX, Yau B, Thomas KC, Wee NKY, Khor EC, Enriquez RF, Vissel B, Biden TJ, Baldock PA, Hoehn KL, Cantley J, Cooney GJ, James DE, Fazakerley DJ (2018) High dietary fat and sucrose results in an extensive and time-dependent deterioration in health of multiple physiological systems in mice. J Biol Chem 293(15):5731-5745. https://doi.org/10.1074/jbc.RA117.000808

42. Schneider K, Valdez J, Nguyen J, Vawter M, Galke B, Kurtz TW, Chan JY (2016) Increased energy expenditure, Ucp1 expression, and resistance to diet-induced obesity in mice lacking nuclear factor-erythroid-2-related transcription factor-2 (Nrf2). J Biol Chem 291(14):7754-7766. https://doi.org/10.1074/jbc.M115.673756

43. Zhou P, Santoro A, Peroni OD, Nelson AT, Saghatelian A, Siegel D, Kahn BB (2019) PAHSAs enhance hepatic and systemic insulin sensitivity through direct and indirect mechanisms. J Clin Invest 129(10):4138-4150. https://doi.org/10.1172/JCI127092

44. Wang YM, Liu HX, Fang NY (2018) 9-PAHSA promotes browning of white fat via activating G-protein-coupled receptor 120 and inhibiting lipopolysaccharide / NF-kappa B pathway. Biochem Biophys Res Commun 506(1):153-160. https://doi.org/10.1016/j. bbrc.2018.09.050
45. Zou T, Wang B, Yang Q, de Avila JM, Zhu MJ, You J, Chen D, Du M (2018) Raspberry promotes brown and beige adipocyte development in mice fed high-fat diet through activation of AMP-activated protein kinase (AMPK) alpha1. J Nutr Biochem 55:157-164. https://doi.org/10.1016/j.jnutbio.2018.02.005

46. Ishibashi J, Seale P (2015) Functions of Prdm16 in thermogenic fat cells. Temperature (Austin) 2(1):65-72. https://doi. org/10.4161/23328940.2014.974444

47. Fernandes-Santos C, Carneiro RE, de Souza ML, Aguila MB, Mandarim-de-Lacerda CA (2009) Pan-PPAR agonist beneficial effects in overweight mice fed a high-fat high-sucrose diet. Nutrition 25(7-8):818-827. https://doi.org/10.1016/j.nut.2008.12.010

48. Syed I, Lee J, Moraes-Vieira PM, Donaldson CJ, Sontheimer A, Aryal P, Wellenstein K, Kolar MJ, Nelson AT, Siegel D, Mokrosinski J, Farooqi IS, Zhao JJ, Yore MM, Peroni OD, Saghatelian A, Kahn BB (2018) Palmitic acid hydroxystearic acids activate GPR40, which is involved in their beneficial effects on glucose homeostasis. Cell Metab 27(2):419-427.e414. https://doi. org/10.1016/j.cmet.2018.01.001

49. Moraes-Vieira PM, Saghatelian A, Kahn BB (2016) GLUT4 expression in adipocytes regulates de novo lipogenesis and levels of a novel class of lipids with antidiabetic and anti-inflammatory effects. Diabetes 65(7):1808-1815. https://doi.org/10.2337/ db16-0221

50. Fujii H, Kawada N (2012) Inflammation and fibrogenesis in steatohepatitis. J Gastroenterol 47(3):215-225. https://doi.org/10.1007/ s00535-012-0527-x

51. Masarone M, Rosato V, Dallio M, Gravina AG, Aglitti A, Loguercio C, Federico A, Persico M (2018) Role of oxidative stress in pathophysiology of nonalcoholic fatty liver disease. Oxid Med Cell Longev 2018:9547613. https://doi.org/10.1155/2018/95476 13

52. Clapper JR, Hendricks MD, Gu G, Wittmer C, Dolman CS, Herich J, Athanacio J, Villescaz C, Ghosh SS, Heilig JS, Lowe C, Roth JD (2013) Diet-induced mouse model of fatty liver disease and nonalcoholic steatohepatitis reflecting clinical disease progression and methods of assessment. Am J Physiol Gastrointest Liver Physiol 305(7):G483-495. https://doi.org/10.1152/ajpgi.00079 .2013

53. Wang YM, Liu HX, Fang NY (2018) High glucose concentration impairs 5-PAHSA activity by inhibiting AMP-activated protein kinase activation and promoting nuclear factor-kappa-B-mediated inflammation. Front Pharmacol 9:1491. https://doi.org/10.3389/ fphar.2018.01491 